\title{
Análisis de un sitio agrícola a través del uso de SIG: una nueva mirada sobre Bajo del Coypar I
}

\section{(4) Cecilia Gentile*}

Fecha de defensa: 17 de Octubre de 2017

Director: Dr. Pablo Tchilinguirian

Co-Directora: Dra. Martina Pérez

Jurados: Dr. Hugo Yacobaccio y Lic. Luis Coll

La presente tesis abordó el estudio de Bajo del Coypar I (BC I), un sitio agrícola ubicado en Antofagasta de la Sierra, Puna de Catamarca. El mismo se conformó a partir del año $1000 \mathrm{AP}$, como respuesta a una fase ambiental de extrema aridez. Durante el siglo XV fue anexado al Tawantinsuyu, lo cual implicó su ocupación y ampliación por parte del imperio Inka. La región de Antofagasta de la Sierra ha sido trabajada sistemáticamente durante más de 20 años (Olivera, 1992; Olivera y Vigliani, 2000-2002; Pérez, 2013; Salminci, 2010, 2011; Tchilinguirian, 2008; Tchilinguirian y Olivera, 2000, 2010). Esta tesis se inserta en los estudios previos de la zona, con la búsqueda de profundizar en el conocimiento sobre este sitio.

El objetivo principal de este trabajo fue conocer la organización social que se hizo cargo de la construcción y mantenimiento de $\mathrm{BC}$ I y acercarnos a sus múltiples dimensiones de uso. También buscamos insertar la problemática dentro de las discusiones respecto de la organización social, política y económica de los grupos que habitaron Antofagasta de la Sierra durante los períodos Tardío e Inka. A partir del uso de dos líneas de evidencia principales, realizamos un análisis de las más de 450 hectáreas que conforman el sitio BC I. Estas líneas son, por un lado, un análisis espacial a partir del uso de un Sistema de Información Geográfica (SIG) y, por el otro, un análisis de cerámica obtenida en recolecciones de superficie.

Hasta el momento, Bajo del Coypar I había sido entendido como una respuesta de las sociedades de Antofagasta de la Sierra ante un escenario climático de aridización creciente. Se relacionaba al sitio con una situación de jerarquización y burocratización, cuyo centro organizativo se hallaba en La Alumbrera, un sitio aglomerado y amurallado aledaño a los campos de BC I (Olivera y Vigliani, 2000-2002). Por otro lado, Salminci (2011) realizó un análisis espacial de BC I y de los recintos de La Alumbrera, con la propuesta de la organización a partir de un sistema de linajes segmentarios, donde coexistían la centralización y descentralización y donde la agricultura estaba organizada a partir de un fuerte control comunal.

\footnotetext{
* Instituto Nacional de Antropología y Pensamiento Latinoamericano, 3 de febrero 1378 (CP C1426BJN) Ciudad Autónoma de Buenos Aires, Argentina. E-mail: chi.gentile@hotmail.com
}

De esta manera, la tesis se relaciona con discusiones actuales que se contraponen a los modelos tradicionales, los cuales asocian la agricultura a gran escala con sociedades centralizadas y burocratizadas (Wittfogel, 1957). Frente a estos planteamientos aparece la propuesta de Erickson (1993), la cual implica tener en cuenta la diacronía presente en el paisaje construido, el cual aparece como monumental en el momento presente, pero cuya construcción puede deberse a una sumatoria de eventos particulares. Esto implica que existe la posibilidad de intensificación agrícola sin la necesidad de un sistema político centralizado. Al respecto, Quesada (2006) hace énfasis en la información que puede obtenerse respecto de organización de una sociedad a partir del estudio de sus redes de riego.

Teniendo en cuenta los estudios preexistentes y las discusiones presentadas se llevó adelante la tesis en cuestión. El objetivo fue conocer la organización de las sociedades que trabajaron sobre $\mathrm{BC}$ I y relacionar el caso particular con las discusiones más amplias respecto de los grupos que habitaron Antofagasta de la Sierra durante el Tardío. Para ello, se realizó un mapeo en un SIG de la totalidad del área productiva. Se tuvieron en cuenta tanto los distintos tipos de parcelas como el sistema de riego. También se mapearon espacios sin parcelas y áreas afectadas por construcciones modernas.

El análisis permitió obtener cálculos ajustados respecto de las dimensiones morfológicas del paisaje agrícola. Asimismo, el estudio de las imágenes satelitales permitió observar determinadas superposiciones entre los diferentes tipos de parcelas basado en la diferenciación realizada por Salminci (2011). Esto probó la existencia de un mínimo de cuatro momentos constructivos. Asimismo, pudimos observar que la estructuración de las parcelas habilita la posibilidad de una construcción modular del espacio, es decir, un agregado paulatino de grupos de parcelas.

Por otro lado, el estudio del sistema de canales de riego confirmó la existencia de dos bocatomas principales, una en el Río Punilla y otra en Los Colorados. El agua proveniente del Punilla era utilizada para la irrigación de las parcelas ubicadas en la terraza aluvial, conducida por un trazado de canales que corrían de Norte a Sur y de Este a Oeste. Por el contrario, el agua de la red Los Colorados alimentaba canales que irrigaban las terrazas y parcelas ubicadas sobre los cerros del Coypar. Este sector está asociado a la ampliación inka de los campos de cultivo. El estudio del trazado de los canales mostró que, si bien la manera en que están estructuradas las parcelas habilita una construcción 
modular, las mismas respetan la red de riego preexistente. Asimismo, la existencia de sólo dos bocatomas demuestra la centralidad de las redes.

El estudio del área sin parcelas también arrojó nueva información, ya que nos permitió observar la presencia de estructuras en aquellos espacios en que no estaba presente el reticulado parcelario. Estas estructuras fueron marcadas y geolocalizadas, para luego ser visitadas en campo. El trabajo en terreno implicó la visita a 15 de las 33 estructuras observadas, sobre las cuales se realizó un relevamiento planimétrico y fotográfico, junto con la recolección superficial de material cerámico y lítico. Las estructuras visitadas fueron caracterizadas y tipificadas en base a sus características morfológicas y técnicas constructivas. Asimismo, el trabajo en campo permitió localizar cinco estructuras nuevas, las cuales no habían sido observadas previamente en las imágenes satelitales.

El material cerámico recolectado en campo fue analizado partiendo de aquellas variables que nos permitieran inferir la posible funcionalidad de los recipientes de los cuales provenía. También registramos aquellos atributos que nos dieran pautas respecto de la adscripción cronológico-cultural de los materiales. En base a las características tecnológicas de los fragmentos, generamos grupos tecnomorfológicos y cuantificamos la presencia de los mismos en las estructuras de las cuales provenía el material.

Los conjuntos cerámicos de las estructuras tenían tres conformaciones muy particulares: por un lado, había conjuntos con una amplia mayoría de cerámica para almacenaje y procesamiento. En segundo lugar, conjuntos cerámicos con mucha presencia de cerámica decorada. Por último, encontramos grupos muy heterogéneos, donde no hay un predominio cerámico asociado a alguna actividad en particular, si no que todos los grupos tecnomorfológicos están presentes de manera relativamente equitativa.

Al cruzar la información de los conjuntos cerámicos y los tipos de estructuras presentes en el área sin parcelas de $\mathrm{BCl}$, observamos que aquellas estructuras arquitectónicamente similares presentan conjuntos cerámicos semejantes entre sí. Al considerar que las características tecnomorfológicas de la cerámica se relacionan con las actividades para las cuales se utilizaron los recipientes, podemos inferir la presencia, e incluso el predominio, de determinadas actividades en las diferentes estructuras.

En base a ello, consideramos que el material cerámico analizado, su densidad, variedad y cantidad, nos permiten plantear el funcionamiento de varias de estas estructuras como espacios residenciales permanentes. Las estructuras presentes en Bajo del Coypar I no estaban estrictamente relacionadas con el almacenaje y la producción, si no que una gran variedad de actividades tenía lugar en las mismas. Consideramos que las estructuras presentan, por un lado, diferentes momentos de ocupación y uso de Bajo del Coypar I y, por el otro, evidencia de la existencia de unidades habitacionales en un área que en trabajos previos se consideró exclusivamente conformada por parcelas.

Todo el trabajo realizado a lo largo de la tesis nos permitió generar información respecto de la organización del área agrícola de Bajo del Coypar I. En primer lugar, conseguimos datos cuantificables y morfológicos de la totalidad del área, los cuales no habrían podido ser obtenidos únicamente a través del trabajo en terreno. En segundo lugar, localizamos más de 15 estructuras, las cuales presentaron una gran cantidad de material arqueológico. Una vez analizada la cerámica de estas estructuras, pudimos confirmar la existencia de lugares de habitación en un área que siempre se había considerado exclusivamente parcelaria. Esto genera nuevas preguntas respecto de la organización y la relación entre $\mathrm{BC}$ I y los sitios aledaños.

Por otro lado, confirmamos que la construcción del paisaje agrícola se realizó de manera paulatina. Logramos identificar con claridad cuatro momentos constructivos, los cuales representan un mínimo de instancias, debido a que la morfología y estructura de las parcelas habilita la posibilidad de agregados modulares de las mismas. Si bien la posibilidad de crecimiento modular existe y en otros sitios ha sido asociada a la existencia de controles a partir de unidades residenciales o familiares, la centralidad de la red de riego implica la necesidad de controles y coordinación por parte de autoridades particulares. Asimismo, se observa que el sitio fue construido siguiendo la pauta arquitectónica de la red de riego principal y sin la apertura de redes independientes, lo cual sugiere un compromiso entre las unidades ejecutoras.

Al calcular el centro geográfico del área de parcelas de Bajo del Coypar I observamos que las estructuras descubiertas se ubican alrededor del mismo, lo cual les otorga acceso y cercanía a la totalidad de los campos cultivados. Ello implica la posibilidad de un control del área productiva por parte de los habitantes de estas unidades residenciales. La presencia del sitio La Alumbrera en las inmediaciones del área agrícola implica una separación espacial entre diferentes segmentos de la población, lo cual puede correlacionarse con cierta división de tareas. Dilucidar la relación entre estos sitios implica la necesidad de estudios a futuro, los cuales permitan conocer las actividades llevadas a cabo en las estructuras presentes en $\mathrm{BC} \mathrm{I}$, así como la relación entre estas unidades y los sitios aledaños. 


\section{Referencias citadas}

»Erickson, C. (1993). The social organization of prehispanic raised field agriculture in the Lake Titicaca Basin. En V. Scarborugh y B. Isaacs (Eds.), Economic Aspects of Water Management in the Prehispanic New World. Research in Economic Anthropology (Supplement 7) (pp. 369-426). Greenwich: JAI Press.

" Olivera, D. (1992). Tecnología y estrategias de adaptación en el Formativo (agro-alfarero temprano) de la Puna Meridional Argentina. Un caso de estudio: Antofagasta de la Sierra (Pcia. de Catamarca, R.A.). (Tesis Doctoral inédita), Universidad Nacional de La Plata, Argentina.

» Olivera, D. y Vigliani, S. (2000-2002). Proceso cultural, uso del espacio y producción agrícola en la Puna Meridional Argentina. Cuadernos del Instituto Nacional de Antropología y Pensamiento Latinoamericano, 19, 459481.

"Pérez, M. (2013). Investigación sobre el Período TardíoInca en las localidades arqueológicas de Antofagasta de la Sierra (Puna Sur) y Cuenca del Río Doncellas (Puna Norte): una aproximación a través de la cerámica. (Tesis Doctoral inédita), Universidad de Buenos Aires, Argentina.

"Quesada, M. (2006). El diseño de las redes de riego y las escalas sociales de la producción agrícola en el 1er milenio DC (Tebenquiche Chico, Puna de Atacama). Estudios Atacameños, 31, 31-46.

»Salminci, P. (2010). Configuración espacial y organización social: análisis de acceso en La Alumbrera (Período Tardío, Puna meridional argentina). Arqueología, 16, 105-124.

»Salminci, P. (2011). Espacios residenciales y productivos, el paisaje arqueológico de Antofagasta de la Sierra entre los siglos XI y XVI d.C. (Tesis Doctoral inédita), Universidad de Buenos Aires, Argentina.

»Tchilinguirian, P. (2008). Paleoambientes holocenos en la Puna austral, provincia de Catamarca (27은): implicancias geoarqueológicas. (Tesis Doctoral inédita), Universidad de Buenos Aires, Argentina.

»Tchilinguirian, P. y Olivera, D. (2000). De aguas y tierras: Aportes para la reactivación de campos agrícolas arqueológicos en la Puna Argentina. Relaciones de la Sociedad Argentina de Antropología, XXV, 99-118.

» Tchilinguirian, P. y Olivera, D. (2010). Agricultura, ambiente y sustentabildad agrícola en el desierto: el caso de Antofagasta de la Sierra (Puna Argentina, 26ㅇ). En M. A. Korstanje y M. Quesada (Eds.), Arqueología de la Agricultura: Casos de Estudio en la Región Andina Argentina (pp. 102-127). Tucumán: Ediciones Magna.

»Wittfogel, K. (1957). Oriental Despotism: A Comparative Study of Total Power. New Haven: Yale University Press. 